\title{
Effects of The Geometer's Sketchpad on Algebraic Reasoning Among Junior Private High School Students
}

\author{
Hwa Li Li ${ }^{1} \&$ Hutkemri Zulnaidi ${ }^{1}$ \\ ${ }^{1}$ Department of Mathematics and Science Education, Faculty of Education, University of Malaya, Kuala Lumpur, \\ MALAYSIA
}

\section{ARTICLE'S \\ INFORMATION}

\section{Article history:}

Received: Oct-14-2019

Accepted: Nov-22-2019

\section{Keywords: Algebraic reasoning abilities,} Geometer's Sketchpad and Junior Two students.

\section{Corresponding address:}

Hutkemri Zulnaidi

E-mail: hutkemri@um.edu.my

\begin{abstract}
Previous studies reported the student's difficulties in algebraic reasoning for solving problems involving quadratic equations. Mostly full to the agreement of understanding and solving quadratic equations is the conceptual challenge in subject mathematics. Integrating technology in the national school curriculum enhances the teaching and learning development throughout the science, engineering and mathematics in the facets of multidiscipline skills and reasoning in context. A quasi-experiment was conducted to determine the effects of Geometer's Sketchpad (GSP)-based instruction through using Geometer's Sketchpad on the algebraic reasoning abilities of Junior Two students. The experimental study was conducted on 60 Junior Two students, who were equally divided into experimental (30 students) and control groups (30 students). The data were collected through algebraic reasoning abilities test. Data were analysed using ANATES 4 and SPSS 25.0. Inferential statistics including the independent sample t-test was used in analyzing the quantitative data obtained. Significant differences were found in the algebraic reasoning abilities of students in relation to quadratic problem solving according to their group type. GSP-based instruction helped students develop their algebraic reasoning abilities in the instructional intervention and provided insights for mathematics educators into utilising the software. Moreover, the effect of the GSP-based instruction enhanced the algebraic reasoning abilities of students without influence of prior knowledge.
\end{abstract}

\section{INTRODUCTION}

Trends in Mathematics and Science Study (TIMSS) is the global mathematics assessment framework on content and cognition, where the former evaluates numbers, algebra, geometry, data and chance, and the latter tests perspectives of knowing, applying and reasoning [1][2]. Malaysia, which is one of the participating countries in Grade 8 (Form Two level) since 1999, gained the ranking of 18th place and showed a non-evident increase of 25 scores in TIMSS 2015. That is, the TIMSS report regarding mathematics performance indicated that only $3 \%$ of Malaysian students achieved the advance international benchmark, 18\% reached high benchmark, 45\% met international benchmark and 34\% hit low benchmark [3]. In 2011, TIMSS results for Grade 8 students indicated poor performance in algebra and questions requiring higher cognitive ability [4]. These results showed unsatisfactory findings and emphasised the need to develop students' algebraic thinking and reasoning in the early grades of secondary school. Students who scored in low and intermediate levels showed capability in constructing, reading and interpreting algebraic manipulations. However, most of them failed to do reasoning when applying and interpreting a variety of problem situations algebraically.

Technological tools promote the active process of learning cognition and cultivate learning and the creative use of knowledge and indulgence to different viewpoints of students [5]. Technology promotes teaching mathematics and makes the learning environment alive and 
attractive [6][7]. [8] and [9] stated that educational systems should be introduced and practiced with technology in the mathematics classroom for active learning mode. Many previous studies have reported improved students' understanding and learning achievement when technological tools were integrated into the teaching and learning of mathematical concepts [10]; [11]; [12]; [13]; [14]; [15]; [16]; [17]; [18]. Moreover, transforming mathematics classroom from the traditional to the technological-based generally led to positive effect and learning attitude [19]; [20]; [21]; [22].

Apart from traditional education with routine algebraic word problems, the educational policy of promoting mathematical thinking and relational understanding shifts the teaching and learning highlight to the open response modelling tasks [23]; [24]; [25]; [26]. In the current educational system, students' engagement in learning algebra can be leveraged with algebraic reasoning through the quantitative reasoning of data changing to the advanced reasoning in analytic geometry, calculus, differential equations and analysis [30]; [27]; [28] Algebraic reasoning heavily depends on personal thinking with quantities and magnitudes as objects in the authentic mathematical modelling [29]. The way of delivering fundamental reasoning abilities in algebra towards students was clarified by [30]. Acquiring such abilities starts with forming a scheme of thinking with magnitude, whereby students will be led to awareness of size, measurement magnitude and relative magnitude, followed by establishing the formation of algebraic learning cloud in thinking. Algebra reasoning is thinking in algebra, generalising quantities using a symbol system and exploring concepts of patterns and functions [31].

The approach to algebra reasoning and developing mathematical thinking is supposedly achieved via algebraic reasoning [32]. Algebraic reasoning is the key understanding in mathematics, functions as scaffolding abstract algebra understanding and allows students to think at high level with magnitudes and relative magnitudes in their exploration in the structure of mathematics [33]. Algebraic reasoning elicits students' learning style with visual, auditory and kinaesthetic and will free the students from focusing on the operational routines and symbolic manipulation in solving sophisticated mathematical problems [34]. Students will be allowed to perform conceptual analysis of related mathematical ideas, where thinking with magnitudes play a vital role for conceiving of change in covarying quantities and obtaining numerical patterns [35]. Therefore, algebraic reasoning can decrease the gap between teachers' thinking and students' thinking that can be profitably exploited in algebra teaching and learning [36].

Students' difficulties in algebraic reasoning for solving problems involve quadratic equations. Understanding and solving quadratic equations is the conceptual challenge in mathematics [37]; [38]; [39]. The existing teaching and learning practice on the topic emphasises procedural aspects of solving quadratic equations without providing the relational understanding variables and graphs of the quadratic equations. Understanding of the behaviour of quadratics and the relationship between the graph and the equation is ignored. [40] revealed that a detailed conjecture of mental constructions blocks the understanding of quadratic equations with improved interrelation of concepts and flexible application of solution approaches. That is, the competencies of flexible algebraic action when dealing with quadratic equations hinder the success of working with and understanding quadratic equations. Many types of errors arise from deficits in procedural understanding on fractions, algebraic processes and conceptual understanding regarding the prerequisite knowledge and solid foundation of algebraic conventions [41]. 
This study aims to investigate the effectiveness of using Geometer's Sketchpad software in developing algebraic reasoning abilities during the teaching and learning procedures. In particular, this study focuses on solving problems involving quadratic equations with one variable. This topic is stipulated in the lower secondary school mathematics syllabus, including independent Chinese secondary schools in Malaysia. According to the previous section, technological tools are the possible instruments that influence students' algebraic reasoning. Thus, the focus of this research is to examine and survey the effect of using technological systems, specifically the Geometer's Sketchpad software, towards the algebraic reasoning abilities of students. Algebraic reasoning includes (1) executing of conjectures, justification, generalisation, explanation and relationships between numerical quantities, (2) making connections with prior knowledge and communicating mathematically between arithmetic and algebra, (3) solving calculations and procedures, (4) checking solutions and (5) interpreting the solutions.

\section{METHODOLOGY}

\section{Research Design}

This study is a quasi-experimental non-equivalent group using a pre- and post-test design. In this study, the researcher compared two groups of respondents, namely, control and experimental. The control group consisted of students in Junior Two class who received traditional classroom instruction using lectures, textbooks and activity books and were expected to use Geometer's Sketchpad software. The experimental group comprised students from another Junior Two class who received quadratic equation tasks that emphasised using Geometer's Sketchpad software in algebraic reasoning in addition to receiving traditional classroom instruction.

\section{Participants}

The participants were Junior Two students from two intact mixed-ability classrooms who have overall medium achievement in the school. All students were 14 years old at the time of the study. The researcher used coin-toss to assign which class is the experimental or control group. Each group had 30 students. No treatment was given to the control group. Students in the control group were taught using traditional methods with text and activity books in class.

\section{Measurement}

Instruments for measuring algebraic reasoning were adapted from [42], who used the fivekey competency framework. Algebraic reasoning assessment consisted of subjective-response tasks based on the criteria covering the algebra content of quadratic equation and had potential to elicit algebraic reasoning competencies. The four constructs and evaluation were based on the five competency levels in algebraic reasoning: (i) Reading and interpreting text and making sense of the context in problem statements, (ii) Identifying salient quantities and relationships between them, (iii) Using algebraic representations of relationships between quantities, (iv) Executing calculations and procedure with precision and checking plausibility of results and $(v)$ Providing convincing explanations that give further insight into the depth of students' algebraic thinking. The strategic algebraic reasoning is a criterion reference assessment and is based on level of algebraic competency developed by [42]. A combination of models was done according to resources from [43], [44] and [45] to identify students' algebraic reasoning competency in 
descriptive algebra. Various sources, including mathematics syllabus, mathematics textbooks, publisher materials and journals of algebraic reasoning, were used to produce an algebraic reasoning test.

This instrument consisted of four constructs that evaluated the abilities in symbolic manipulation, conceptual understanding, analytic skills and word problem solving. The first, second and third constructs had 10,3 and 5 questions. The experimental and control groups of students were required to answer 21 items in the pre- and post-tests. The items were constructed with the quadratic equation problematic context, which required students to make calculations, interpretations or explanation. The score of each item was given according to the level of competency, as suggested by [42], that students could achieve.

Each level of achievement was given a mark of one. The five competencies in algebraic reasoning were assigned a full mark of five. The first and second constructs measured the students' algebraic reasoning from level one to three only. The third construct evaluated the algebraic reasoning competency up to level four. The last construct involving word problems tested the algebraic reasoning up to level five. The reliability of the algebraic reasoning test involving 30 students was analysed using Cronbach Alpha in SPSS version 25 and obtained a Cronbach Alpha value of 0.780. An instrument with Cronbach Alpha value above 0.70 would be considered reliable. However, the result of the difficulty index and discriminant index were accepted with a range of 30\% above for each item [46].

\section{Data analysis}

The results were further analysed using SPSS software version 25. Paired sample t-tests were conducted on the two groups to determine any difference between the students' learning on algebra topic for quantitatively analysing the collected data. Every individual in the sample was measured twice using the similar test before and after a period, and the two-measurement data were compared. The data of the dependent variable were in interval scale. The test was used to find any improvement in the algebraic reasoning competency between the pre- and post-tests of the experimental group.

\section{RESULTS AND DISCUSSION}

\section{Difference in pre-test of algebraic reasoning abilities between the experimental and control groups}

Before hypothesis testing, the assumption test for normality was performed. Firstly, the result of the Shapiro-Wilk test indicated the statistics of 0.971 and 0.965 , with the p-values of 0.564 and 0.405 for the experimental and control groups, respectively. This result meant that the p-value was greater than 0.05 and that the assumption of normality for each group was not violated.

Table 1. Results of the independent sample t-test in pre-test of algebraic reasoning assessment

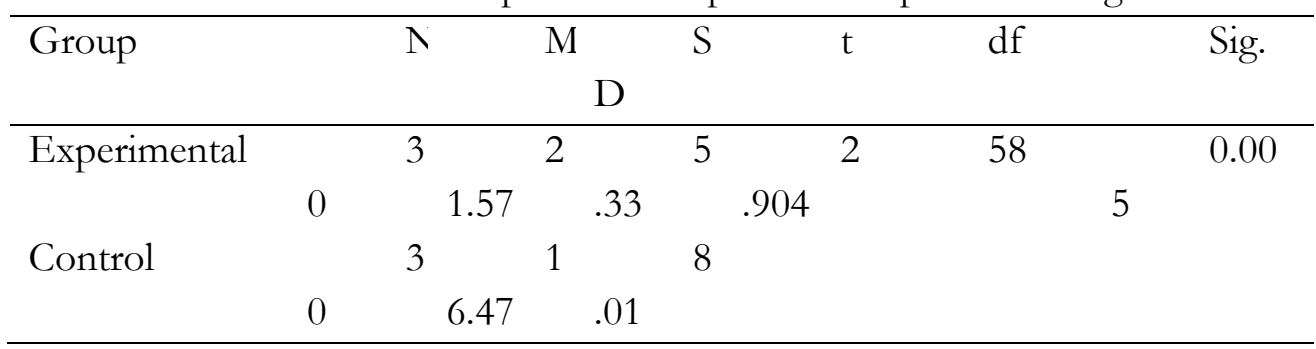


The results of the independent samples t-test, which referred to the pre-test of algebraic reasoning competency, in Table 1 showed that the experimental $(\mathrm{N}=30, \mathrm{M}=21.57$ and $\mathrm{SD}=$ 5.33) and the control groups $(\mathrm{N}=30, \mathrm{M}=16.47$ and $\mathrm{SD}=8.01)$ had the t-value of 2.904, with the degree of freedom of 58 and the p-value of 0.005 . A p-value less than 0.05 meant that the null hypothesis was rejected. The findings concluded a significant difference in the pre-test between the experimental and control groups. Moreover, the mean rank of the experimental group (21.57) was higher than that of the control group (16.47). Thus, the students in the experimental group possessed higher algebraic reasoning competency before the intervention period than those in the control group. This result indicated that the students in the experimental group had significantly higher algebraic reasoning competency than those in the control group before the intervention period at 5\% level of significance. Therefore, the experimental group had better algebraic reasoning competency than the control group in solving quadratic problems before intervention.

\section{Difference in post-test of algebraic reasoning competency between the experimental and control groups}

Prior to hypothesis testing, the assumption test of normality was conducted. The result of the Shapiro-Wilk test indicated the statistics of 0.932 and 0.937 , with the p-values of 0.056 and 0.076 for the experimental and control groups, respectively. A p-value greater than 0.05 meant that the assumption of normality for each group was not violated.

Table 2. Results of the independent sample t-test in post-test of algebraic reasoning assessment

\begin{tabular}{lcccccc}
\hline Group & $\mathrm{N}$ & $\mathrm{M}$ & $\mathrm{SD}$ & $\mathrm{t}$ & $\mathrm{df}$ & $\mathrm{Sig}$ \\
\hline Experimental & 30 & 4 & 5.17 & 5.180 & 58 & 0.001 \\
Control & 30 & 0.90 & & & & \\
& & 3 & 7.27 & & & \\
\hline
\end{tabular}

The results of the independent samples t-test, which referred to the pre-test of algebraic reasoning competency, showed that the experimental group $(\mathrm{N}=30, \mathrm{M}=40.90$ and $\mathrm{SD}=5.17)$ and the control group $(\mathrm{N}=30, \mathrm{M}=32.47$ and $\mathrm{SD}=7.27$ ) had the t-value of 5.180, with the degree of freedom of 58 and the p-value of less than 0.05 . This result indicated that the null hypothesis was rejected. The findings concluded a significant difference in the post-tests of the experimental and control groups. Furthermore, the mean rank of the experimental group (40.90) was higher than that of the control group (32.47). Thus, the experimental group possessed higher algebraic reasoning competency after the intervention period than the control group. This result indicated that the students in the experimental group had significantly higher algebraic reasoning competency than those in the control group after the intervention at $5 \%$ level of significance. Therefore, GSP-based instruction on the quadratic problem solving using Geometer's Sketchpad improved the algebraic reasoning competency of students compared with traditional instruction.

The results of the independent sample t-tests on students' pre-algebraic reasoning competency indicated that the algebraic reasoning amongst the students in the experimental and control groups differed significantly before this study was performed. The students in the experimental group were assumed to possess slightly higher algebraic reasoning competency than those in the control group before the instructional intervention. The findings were concluded parallel with the researcher's assumption of a significant difference. This finding was consistent with the quasi-experimental study conducted by [47], in which their students' suicide awareness and prevention score before the study was conducted differed significantly. Students in the 
experimental group seemed to perform slightly better than those in the control group according to the data of means and standard deviations. [48] found that the mathematical learning achievement and problem-solving abilities of the experimental and control groups differed significantly before intervention of the teaching methods. In addition, student scores reflected their initial algebraic levels of algebraic reasoning ranged from low to medium. This result was consistent with the research conducted by [4] on algebraic thinking of Grade 8 students in the pre-test. [49] stated that middle school students scored low on the mathematical equivalence and the formal algebraic reasoning based on their pre-stage of the primary educational instruction. In addition, [50] reported low performance on core algebra content assessment before their study was conducted.

The results of the findings on the independent sample t-test revealed that students in the experimental group had a significant difference and improved better than those in the control group. The improvement was shown in students' algebraic reasoning competency after the GSPbased instructional intervention of quadratic problem solving using Geometer's Sketchpad was given. The result was consistent with the meta-analysis that showed students in the experimental group scoring significantly different and having higher mathematical achievement in the post-test than those in the control group after implementing the dynamic-geometry-software-based instructional activities [51] and emphasising on the conceptual understanding with less overt algebraic functionality [52]. [53] claimed that the GSP-based instruction on derivatives enhanced students' derivative mathematical reasoning. The experimental group showed higher post-test achievement after computer-assisted intervention and had higher retention and attitude scores than the control group [21]. On the basis of a similar result, the GSP-aided instruction revealed that the experimental group performed significantly better than the control group regardless of the gender factor due to students having the chance to use concrete learning aids [7].

This study had reported the potential and effect of GSP-based instruction of quadratic problem solving using Geometer's Sketchpad programs. The algebraic reasoning competency amongst students in the experimental group improved significantly after the GSP-based intervention. This method of instruction of quadratic problem solving in the classroom activities designed with Geometer's Sketchpad usage was useful and effective in guiding students' learning of solving quadratic problems compared with the traditional instruction using chalk-and-talk approach. This result was consistent with the research done by Adulysas and Abdul Rahman (2014), who concluded that the use of Geometer's Sketchpad under teacher's guidance and instruction helped middle school students perform better. Their mathematical thinking was enhanced, as indicated by the quantitative statistics and mathematical reasoning in the qualitative data. Students actively participated in the GSP-based instructional classroom using Geometer's Sketchpad, where collaborative learning was allowed [54]. Their communication skills in algebra reasoning improved when students worked together with their peers and exercised their mathematical thinking during the classroom problem-solving processes. They learnt to justify and explain their solutions throughout the GSP-based instruction using the Geometer's Sketchpad. [55] suggested that students who had hand-on activities using the dynamic mathematics system gained positive effect on learning and mastering conceptual understanding in mathematics well.

The findings from this study have several implications for algebraic reasoning competency based on the learning theory of distributed cognition. The significant improvement in the algebraic reasoning competency amongst students in the experimental and control groups supported the major assumption of the learning theory of distributive cognition that learners can 
be active entities and learnt by working together to solve the tasks by using technological tools, such as Geometer's Sketchpad. This way encourages the process of cognition and knowledge about the problem solving on quadratic topics distributed across students, worksheets and the dynamic and collaborative GSP-based platform in the learning environment. The encouraging findings of this research suggested that Geometer's Sketchpad could be a useful tool in teaching quadratic problematic solving in the secondary school level. Students from different background might result in varying findings in using this tool and should thus be considered to enhance the exploration and explanation of the findings of this study.

\section{CONCLUSIONS AND SUGGESTIONS}

This study showed the potential and effect of GSP-based instruction of quadratic problem solving using Geometer's Sketchpad programmes. The algebraic reasoning competency amongst students in the experimental group improved significantly after GSP-based intervention. The GSP-based instruction of quadratic problem solving in the classroom activities designed with Geometer's Sketchpad usage was useful and effective to guide students' learning of solving quadratic problems compared with the traditional instruction using chalk-and-talk approach. The dynamic mathematics software, such as Geometer's Sketchpad, played a vital role in enhancing students' participation and interest in discovering mathematical concepts instead of developing students' mathematical thinking and reasoning. The implementation of the interactive mathematics software in mathematical learning activities allowed students to engage into deeper mathematical thinking, such as algebraic reasoning.

\section{REFERENCES}

[1]Grønmo, L. S., Lindquist, M., Arora, A., \& Mullis, I. V. (2015). TIMSS 2015 mathematics framework. TIMSS, 11-28.

[2]Mullis, V.S., Martin, M.O., Foy, P., \& Hooper, M. (2015). TIMSS 2015 International results in mathematics. IEA.

[3] Ministry of Education Malaysia. (2016). TIMSS Report 2015. Retrieved from https://www.moe.gov.my/images/Terbitan/Rujukan-Akademik/pubfile_file_002124.pdf

[5] Cunska, A., \& Savicka, I. (2012). Use of ICT teaching-learning methods make school math blossom. Procedia-Social and Behavioral Sciences, 69: 1481-1488.

[4] Siew, N. M., Geofrey, J., \& Lee, B. N. (2016). Students' algebraic thinking and attitudes towards algebra: the effects of game-based learning using Dragonbox 12+ App. The Research Journal of Mathematics and Technology, 5(1): 66-79.

[6] Kilpatrick, J. (2014). History of research in mathematics education. Encyclopaedia of Mathematics Education, 267-272. Springer Netherlands.

[7] Tai, C. H., Leou, S., \& Hung, J. F. (2018). Effectiveness of GSP-Aided Instruction. K-12 STEM Education: Breakthroughs in Research and Practice, 430-446. IGI Global.

[8] Reys, R., Lindquist, M., Lambdin, D. V., \& Smith, N. L. (2014). Helping Children Learn Mathematics. John Wiley \& Sons.

[9] Lee, D., Morrone, A. S., \& Siering, G. (2018). From swimming pool to collaborative learning studio: Pedagogy, space, and technology in a large active learning classroom. Educational Technology Research and Development, 66(1): 95-127.

[10] Furner, J. M., \& Marinas, C. A. (2007). Geometry Sketching Software for Elementary Children: Easy as 1, 2, 3. Eurasia Journal of Mathematics, Science \& Technology Education, 3(1): 83-91. 
[11] Patsiomitou, S. (2008). The development of students geometrical thinking through transformational processes and interaction techniques in a dynamic geometry environment. Issues in Informing Science and Information Technology Journal, 5: 353-393.

[12] Sheehan, M., \& Nillas, L. (2010). Technology integration in secondary mathematics classrooms: Effect on students' understanding. Journal of Technology Integration in the Classroom, 2(3): 67-83.

[13] Gecu, Z., \& Satici, A. F. (2012). The effects of using digital photographs with Geometer's Sketchpad at 4th grade. Procedia-Social and Behavioral Sciences, 46: 1956-1960.

[14] Leong, K. E. (2013). Impact of Geometer's Sketchpad on Students Achievement in Graph Functions. Leong, KE (2013). Impact of Geometer's Sketchpad on Students Achievement In Graph Functions. Malaysian Online Journal of Educational Technology, 1(2): 19-33.

[15] Zhang, M., Trussell, R. P., Gallegos, B., \& Asam, R. R. (2015). Using math apps for improving student learning: An exploratory study in an inclusive fourth grade classroom. TechTrends, 59(2): $32-39$.

[16] Estapa, A., \& Nadolny, L. (2015). The effect of an augmented reality enhanced mathematics lesson on student achievement and motivation. Journal of STEM Education: Innovations and Research, 16(3): 4048.

[17] Denton, J. (2017). Transforming mathematics: Using dynamic geometry software to strengthen understanding of enlargement and similarity. Warwick Journal of Education, 1: 69-84.

[18] Ng, W. L., Teo, B. C., Yeo, J. B., Ho, W. K., \& Teo, K. M. (2019). Use of Technology in Mathematics Education. Mathematics Education in Singapore, 313-348. Springer, Singapore.

[19] Abdelfatah, H. (2011). A story-based dynamic geometry approach to improve attitudes toward geometry and geometric proof. ZDM Mathematics Education, 43(3), 441-450.

[20] Cheung, A. C., \& Slavin, R. E. (2013). The effectiveness of educational technology applications for enhancing mathematics achievement in K-12 classrooms: A meta-analysis. Educational Research Review, 9: 88-113.

[21] Pilli, O., \& Aksu, M. (2013). The effects of computer-assisted instruction on the achievement, attitudes and retention of fourth grade mathematics students in North Cyprus. Computers \& Education, 62: 62-71.

[22] Almeqdadi, F. (2018). The effects of using an interactive software (GSP) on UAE students' attitudes towards geometry. Humanities, 3(1), 22-28.

[23] Blomhøj, M., \& Kjeldsen, T. H. (2013). Students' Mathematical Learning in Modelling Activities In Teaching Mathematical Modelling: Connecting to Research and Practice. Springer, Dordrecht.

[24] Mueller, M., Yankelewitz, D., \& Maher, C. (2014). Teachers promoting student mathematical reasoning. Investigations in Mathematics Learning, 7(2): 1-20.

[25] Baron, L. M. (2015). An authentic task that models quadratics. Mathematics Teaching in the Middle School, 20(6), 334-340.

[26] Buhrman, D. (2017). The Design and Enactment of Modelling Tasks: A Study on the Development of Modeling Abilities in a Secondary Mathematics Course. Public Access Theses and Dissertations from the College of Education and Human Sciences. http://digitalcommons.unl.edu/cehsdiss/282

[27] Carraher, D. W., Martinez, M. V., \& Schliemann, A. D. (2008). Early algebra and mathematical generalization. ZDM Mathematics Education, 40(1): 3-22.

[28] Johnson, H. L. (2013). Reasoning about quantities that change together. Mathematics Teacher, 106(9): 704-708.

[29] Smith, J. P. J., \& Thompson, P. W. (2017). Quantitative reasoning and the development of algebraic reasoning. Algebra in The Early Grades:117-154. Routledge.

[30] Thompson, P. W., Carlson, M. P., Byerley, C., \& Hatfield, N. (2014). Schemes for thinking with magnitudes: An hypothesis about foundational reasoning abilities in algebra. In K. C. Moore, L. P. Steffe \& L. L. Hatfield (Eds.), Epistemic algebra students: Emerging models of students' algebraic knowing., WISDOMe Monographs, 4: 1-24. Laramie, WY: University of

[31] Van de Walle, J. A., Karp, K., \& Bay-Williams, J. (2011). Elementary and middle school mathematics: Teacbing developmentally. Boston, MA: Allyn \& Bacon.

[32] Bednarz, N., Kieran, C., \& Lee, L. (1996). Approaches to Algebra: Perspectives for Research and Teaching. Dordrecht, Boston: Kluwer Academic Publishers.

[33] Kaput, J. J., Carraher, D. W., \& Blanton, M. L. (2017). Algebra in The Early Grades. Routledge.

[34] Indraswari, N. F., Budayasa, I. K., \& Ekawati, R. (2018). Algebraic Reasoning in Solving Mathematical Problem Based on Learning Style. Journal of Physics: Conference Series, 947(1): 1-6. 
[35] Johnson, H. L. (2014). Images of intensive and extensive quantity: A framework for reasoning about change in covarying quantities. In Epistemic Algebraic Students: Emerging Models of Students' algebraic Knowing Papers from An Invitational Conference, 267-280. University of Wyoming College of Education.

[36] Goos, M., Vale, C., \& Stillman, G. (2017). Teaching Secondary School Mathematics: Research and Practice for the 21st Century. Allen \& Unwin.

[37] Kotsopoulos, D. (2007). It's like hearing a foreign language. Mathematics Teacher, 101(4): 301-305.

[38] Didiş, M. G., Baş, S., \& Erbaş, A. (2011). Students' reasoning in quadratic equations with one unknown. The Seventh Congress of the European Society for Research in Mathematics Education (CERME7): 479-489.

[39] Didis, M. G., \& Erbas, A. K. (2015). Performance and difficulties of students in formulating and solving quadratic equations with one unknown. Educational Sciences: Theory and Practice, 15(4): 11371150.

[40] López, J., Robles, I., \& Martínez-Planell, R. (2016). Students' understanding of quadratic equations. International Journal of Mathematical Education in Science and Technology, 47(4): 552-572.

[41] Kanbir, S., Clements, M. K., \& Ellerton, N. F. (2018). Historical Reflections on How Algebra Became a Vital Component of Middle-and Secondary-School Curricula. In Using Design Research and History to Tackle a Fundamental Problem with School Algebra, 11-58. Springer, Cham.

[42] Lepak, J. R., Wernet, J. L., \& Ayieko, R. A. (2018). Capturing and characterizing students' strategic algebraic reasoning through cognitively demanding tasks with focus on representations. The Journal of Mathematical Behavior, 50: 57-73.

[43] NRC (2001). Adding it up: Helping children learn mathematics. National Academies Press.

[44] Blanton, M. L., \& Kaput, J. J. (2005). Characterizing a classroom practice that promotes algebraic reasoning. Journal for Research in Mathematics Education, 36(5): 412-446.

[45] Kieran, C. (2004). Algebraic thinking in the early grades: What is it. The Mathematics Educator, 8(1): $139-151$.

[46] Karno To. (1996). Knowing Text Analysis (Introduction to ANATES Computer Program). Bandung: Department of Educational Psychology and Guidance FIP IKIP.

[47] Shannonhouse, L., Lin, Y. W. D., Shaw, K., \& Porter, M. (2017). Suicide intervention training for K12 schools: A quasi- experimental study on ASIST. Journal of Counselling \& Development, 95(1): 3-3.

[48] Rattanatumma, T., \& Puncreobutr, V. (2016). Assessing the effectiveness of STAD model and problem-based learning in mathematics learning achievement and problem-solving ability. Journal of Education and Practice, 7(12): 194-199.

[49] Fyfe, E. R., Matthews, P. G., Amsel, E., McEldoon, K. L., \& McNeil, N. M. (2018). Assessing formal knowledge of math equivalence among algebra and pre-algebra students. Journal of educational psychology, 110(1): 87-101.

[50] Martinez, M. V., Bragelman, J., \& Stoelinga, T. (2016). Underprepared Students' Performance on Algebra in a Double-Period High School Mathematics Program. Mathematics Educator, 25(1): 3-31.

[51] Chan, K. K., \& Leung, S. W. (2014). Dynamic geometry software improves mathematical achievement: Systematic review and meta-analysis. Journal of Educational Computing Research, 51(3): 311-325.

[52] Mackrell, K. (2012). Introducing algebra with interactive geometry software. Electronic Journal of Mathematics \& Technology, 6(1): 96-114.

[53] Troup, J. (2019). Developing Reasoning about the Derivative of a Complex-Valued Function with the Aid of Geometer's Sketchpad. International Journal of Research in Undergraduate Mathematics Education, 5(1): 3-26.

[54] Shaffer, D. W. (2013). Design, collaboration, and computation: The design studio as a model for computer-supported collaboration in mathematics. CSCL 2: 219-250. Routledge.

[55] Alkhateeb, M. A., \& Al-Duwairi, A. M. (2019). The Effect of Using Mobile Applications (GeoGebra and Sketchpad) on the Students' Achievement. International Electronic Journal of Mathematics Education, 14(3), 523-533. 


\section{BIOGRAPHY}

\section{Hwa Li Li}

She obtained his Bcs (2011) in Cognitive Science from University Malaysia Sarawak and Med (2019) in Mathematics Education from University of Malaya. Currently she has appointed as senior teacher at Department of Mathematics at one of the Chinese Private High School at Kuala Lumpur. Phone:+60186630722, Email: cannonhwa@gmail.com.

\section{Hutkemri Zulnaidi}

He obtained his Bed (2006), Med (2009) and PhD (2013) in Mathematics Education from Universitas Riau (UR) and National University of Malaysia (UKM). Currently he has appointed as senior lecturer at Department of Mathematics and Science Education lecturer at the University of Malaya. Phone: +60379675011, Email: hutkemri@um.edu.my. 